\title{
Chief Information Officers Organization Adopts Ambitious Program
}

The International Academy of Chief Information Officers (IAC) held their General Meeting in Bangkok, Thailand on June 29-30. Participating were representatives of IAC chapters in 10 countries, CIOs and other officials from several governments and international organizations. The main purposes of the IAC (www.iacthailand.org) are to foster learning and development of CIOs in many nations with its activities including academic research and policy dialogues in the field of CIO development that include organizing workshops, conventions and symposia. IAC also prepares reports and recently sponsored the book Global e-Governance: Advancing e-Governance Through Innovation and Leadership, published by IOS Press.

Participants were welcomed by Dr.Thaweesak Koanantakool, vice President of the National Science and Technology Development Agency (NSTDA) Ministry of Science and Technology, Thailand, on behalf of Dr. Pairash Thajchayapong, president of the IAC. The theme of the 2009 conference was "Innovative CIO in the Economic and Environment Crisis," of high interest and concern of government and private sector leaders around the world. He congratulated members of IAC chapters from China, Cambodia, Japan, Korea, UK, Singapore, India, Macao, Peru, Russia, Vietnam, South Africa, Taiwan and the United States for participating. This 4th IAC General Meeting," Thaweesak said, is expected to mark several milestones for CIO community development. These include the establishment of an International CIO University Training Center, Global Accreditation Program, and development programs in collaboration with the ITU and APEC-TEL.

"To date," Thaweesak indicated, "CIOs in both public and private sectors have realized their mandates increasingly complicated. ICT and e-Government applications nowadays are poised to serve citizen's needs and demands and integration of business functions within and between organizations. This phenomenon creates a real need for CIOs to cooperate through a proper channel or forum where they can organize networking, collaborate and share valuable resources, technology and knowledge. This cooperation may become the foundation for joint efforts to fulfill their responsibilities to serve their governments and countries."

"Chief Information Officers have been renamed Chief Innovation Officers in a number of organizations. The IAC supports this new standards and will encourage all its member chapters to work out such initiatives to achieve this goal and make innovation sustainable in the long run," Thaweesak stated.

The keynote address was delivered by Dr. Pansak Sirirachatapong, Director of NSTDA, Thailand. He welcomed Professor Toshio Obi, Director of the APEC e-Government Research Center and e-Government Program at Waseda University, as IAC President-elect.to serve from July 1, 2009, for the next three years. $\mathrm{He}$ commended IAC for opening a new era for CIOs and ICT development. "We have closely collaborated among local chapter members and communities on R\&D and capacity building for CIO development."

During the General Meeting, Obi presented the new Vice Presidents for the coming three years. They are Prof. J.P Auffret, to represent North America; Prof. Matthias Finger, to represent Europe and Mrs. Jantima Sirisaengtaksin, to represent Asia. Dr. Pairash was appointed Honorary IAC President, Russell Pipe appointed Advisor to IAC, and Jirapon Tubtimhin has been re-appointed Secretary General.

\section{IAC Accreditation Center and Global Resource Center}

An a progress report on an initiative to establish an 
IAC Global Accreditation Center (GAC) led by Prof. J.P. Auffret of the US Chapter was presented. The GAC aims to promote and enhance the development and quality of CIO and Executive IT Leadership programs in developing countries. Through a network of partnerships with universities, private sector corporations, governments and NGOs, the GAC is to develop metrics for quality curricula and best practices for the CIO and Executive IT Leadership education field.

The General Meeting endorsed the GAC program for CIO and Executive IT Leadership advancement that is intended to connect program administrators and educators around the world with similar goals of providing quality $\mathrm{CIO}$ education consistent with current and future e-Government challenges.

To supplement the GAC efforts for regions and countries that are beginning to develop CIO and Executive IT Leadership programs in advance of accreditation, a Global Resource Center (GRC) is to be established. It will address preparing necessary implementing policies, regulations and structures for $\mathrm{CIO}$ and Executive IT Leadership, and will champion the adoption of enabling policy, regulatory, organizational and technology frameworks for cross-agency and cross-ministry coordination.

The IAC GRC also will make available conceptual models for developing CIO and Executive IT Leadership programs and standard curricula for CIO education in the public sector. It will be targeted for the needs of developing countries at different stages of eGovernment and ICT development; establish guidelines for tailoring standard curricula to local needs and circumstances and educational modules to implement concrete curricula. The materials of the IAC GAC will be vetted and subject to standards on formats and quality.

The IAC GAC and GRC Initial Advisory Board was formed composed of members from the public and private sectors and academics from several regions of the world. The Board is to organize its work program, develop timelines and business plan, and a vetting procedure for the Accreditation Program during the next 12 months.

\section{APEC E-Government Research Center}

Prof. Toshio Obi chaired the Advisory Committee of the APEC E-Government Research Center, operating at Waseda University. The Center has been approved to continue as an extension project under APECTEL.
The advisors reviewed present cooperation and possible future collaboration with the IAC. A number of suggestions were presented by advisors, such as collaboration and joint initiatives with several IAC member countries. This could include having a special one-day workshop at the 2010 IAC Annual Meeting; cooperating on a project on Intellectual Property Protection, and establish a visiting scholars program.

\section{UNU Center for Electronic Governance - IAC Cooperation Agreement}

During the Annual meeting an agreement was signed between IAC and the United Nations University Center for Electronic Governance in Macao "to partner on joint initiatives as well as support individual UNU Center for Electronic Governance and IAC e-Government initiatives." These will include:

IAC will promote UNU ICEGov annual conferences through development of joint workshops and submission of current case studies and e-Government research papers.

Jointly develop a Global Resource Center (GRC) along the lines as approved by IAC. In particular, the GRC would be oriented toward institutional members and communities of practice to individuals. These would include academics, educations and researchers who are interested in developing CIO and Executive IT Leadership programs. The GRC is to include measures to enable policy-making, regulation and structures for CIO and Executive IT Leadership.

\section{IAC Future Activities}

The next International IAC Conference is to be held in Bandung, Indonesia in May 2010, hosted by the Bandung Institute of Technology. The theme, announced by Prof. Suhono Harso Supangkat will be "Answering the future of the $\mathrm{CIO}$ in the rapidly changing $\mathrm{C}$ Generation Society." This new generation society, it was explained, has as its main characteristics: Connectivity, Collaboration, Content, Creative, and Contextual features. Questions such as "What is the role of $\mathrm{CIO}$ in this ever-changing situation? How to guide the development of a nation?" This conference is to provide an avenue for researchers, government officials, developers, analysts, academics, industrial sectors, and authorities of all stake holder in the ICT field to share their vision, experience and ideas. 
The General Meeting endorsed participation by IAC members at a number of international meetings scheduled during the next 12 months. A Distance Education and Training Program on CIOs is being supported by UNESCO and APEC. Programs are expected to be held involving Japan-China, Japan-Thailand and Japan-Russia. Joint Research Projects are planned including Intelligent Transport Systems (ITS) involving Japan and Thailand; E-Government for Ageing Societies involving Japan and the EU; and E-Government Rankings 2010 by Waseda University. IAC is planning to collaborate on Journal of e-Governance, establish an IAC Newsletter and an IAC homepage. The General Meeting approved the Bangkok Statement that elaborates on many of the challenges and issues raised during the Annual Meeting (Text Follows)

\section{Bangkok Statement}

The International Academy of CIO (IAC) International Forum 2009 was held simultaneously with the 4th IAC Annual General Meeting on June 29-30, 2009 in Bangkok, Thailand. Participants from 15 countries and economies as well as 5 International organizations and 5 local Universities took part in the activities of the program. We, the participants, would like to express our deepest gratitude to the organizers of this conference, especially IAC Thailand.

The conference was organized under the theme "Innovative $\mathrm{CIO}$ in the Economic and Environment Crises", in order to stress the role ICT play in solving the problems that arise in a worldwide crisis scenario. High quality presentations given by academia, business and government, showed the latest researches and development on the following issues:

1. Economic crisis and E-Government Programs,

2. Next Generation E-Government and E-Municipality,

3. Applications for E-Government and ICT,

4. Global Agenda on Open Standard, IPR, Knowledge Management and Innovations.

5. Smart Government

6. CIO and Executive IT Leadership

The role of ICT was highlighted as an enabler and a tool to effectively deal with the problems arising with the worldwide economic crisis by generating synergies in the management of productive activities. In the field of environment protection, "Green ICT" is proving to be a key component of the strategies by governments and industries to support an increase in productivity complying with the protection of the environment.

ICT effectively can support efforts to improve living conditions worldwide. However, in order to fully utilize ICT, we have reached to the conclusion that further actions in the field of ICT capacity building are required. These two days of productive discussions and ideas exchanged, allow us to endorse the following agenda and further actions:

1. The MOU which was signed between IAC and UNU to Collaborate within the context of CIO studies as well as related activities (As per attachment)

2. Support and improve the existing collaboration among academia, governments, business sectors, international organizations, and other related parties for the rapid development of eGovernment as a tool to overcome the worldwide economic and environmental crises.

3. Strengthen the development and implementation of the CIO model by IAC endorsed by APEC around the world by supporting "International Accreditation Program for CIO studies" at a graduate level, adapting them to the particular conditions of countries where these programs are implemented.

4. Continue with the existing research on the new roles for the CIO in an innovative approach, focusing on the main existing problems worldwide, economic and environmental crises, and the rapid aging of citizens.

5. Foster the development of "Green ICT", in order to preserve the environment. This will be done by complying with the standards defined by the industry and international organizations. Support is also required for monitoring activities aiming at protection of the environment. In this context, Intelligent Transport System (ITS) is one of the very effective measures to overcome.

6. In a worldwide crisis context, the usage of ICT to support distance learning (e-learning) can enormously benefit developing countries by reducing the associated costs for education provision.

7. Universities have to play an active role by both creating and diffusing appropriate contents to be delivered by ICT. In this sense, we consider that:

(a) ICT are not only an exclusive tool to provide distance learning solutions, but in addition, it is required to integrate the 'traditional' ed- 
ucation models so as to give an additional education channel. The role of universities in proposing new education schemes is fundamental.

(b) All the efforts put in using ICT for education are not going to be useful if there is not an appropriate training on the usage of ICT. To this extent, training programs and tutorials have to be adapted to the socio-economic conditions of the targeted communities

8. The collaboration between governments and the private sector through PPP is necessary in a world economic crisis. Joint efforts can be beneficial to government, businesses and citizens as a new type of e-Community. To accomplish this goal, it is necessary to analyze the existing collaboration schemes and modify them if necessary in order to turn them more efficient.

9. Support the further development of e-Municipality and municipal e-Government to the next challenges of catalyzing economies development, urbanization and aging societies.

10. In order to allow continuous innovation the protection of Intellectual Property Rights (IPR) is somewhat an urgent agenda. Experience show that countries with an appropriate legal framework to protect IPR can enjoy the benefits of constant innovation and improvement of their quality of life.

Considering the benefits of this conference, we would like to propose, conclude our stances and to expose for other interested parties as followings:
- To organize international conferences as the ideal space to interchange research outcomes as well as best practices and to discuss future trends related to capacity building and the role of the Governmental CIO through APEC e-Government/CIO scheme.

- To establish a global green ICT network to analyze and monitor abnormal situations regarding ICT usage in the global society, with the collaboration among international organizations such as APEC, ASEAN, ITU, OECD and the United Nations University which can support the efforts in building a better world.

- To include in the training program for CIO the necessary competences to deal with issues such as the economic and environmental crises as well as to highlight the importance of the $\mathrm{CIO}$ in an aging society.

- To expand the activities carried out by UNESCO/UNITWIN (University Twining and Networking) on distance education (APDMEN), as well as the APEC ICT HRD training scheme.

- To promote the Global Resource Center (GRC) as an extension of the "IAC Accreditation Program" for the CIO university network as well as to promote at the same time the creation of communities of practices as mechanism for implementation of the GRC

IAC endorsed the proposal by Indonesia Chapter to host the Next General Meeting in Bandung, Indonesia in 2010 during the month of May/June in conjunction with "e-Indonesia Initiative 2010". 